\title{
Deep Brain Stimulation in the Setting of Cochlear Implants: Case Report and Literature Review
}

\author{
Thomas J. Buell $^{a} \quad$ Alexander Ksendzovsky ${ }^{a, d}$ Binit B. Shah ${ }^{b}$ Bradley W. Kesser ${ }^{c}$ \\ W. Jeffrey Elias ${ }^{a}$ \\ Departments of a Neurosurgery, ${ }^{b}$ Neurology and c Otolaryngology, University of Virginia, Charlottesville, Va., and \\ dSurgical Neurology Branch, National Institute of Neurological Disorders and Stroke, National Institutes of Health, \\ Bethesda, Md., USA
}

\section{Key Words}

Deep brain stimulation · Parkinson's disease $\cdot$ Cochlear implant

\begin{abstract}
Background/Aims: As technology continues to advance for our aging population, an increasing number of deep brain stimulation (DBS) candidates will have preexisting implanted electrical devices. In this article, we discuss safe and successful DBS in a patient with Parkinson's disease (PD) and bilateral cochlear implants. Methods: A 70-year-old male with PD and bilateral cochlear implants underwent successful microelectrode-guided DBS implantation into bilateral subthalamic nuclei (STN). The patient's cochlear implant magnets were removed and replaced in the outpatient clinic for preoperative MRI and stereotactic targeting. The cochlear implants were turned off intraoperatively for STN microelectrode recordings. Results: Precise, MRI-guided stereotactic DBS implantation was possible. Intraoperative high-fidelity microelectrode recordings confirmed STN neurons with the cochlear implants turned off. These recordings were not possible with active cochlear implant devices. Our literature review describes the other approaches/techniques that have been used to manage DBS surgery in the setting
\end{abstract}

of cochlear implants. Conclusions: Despite the risk of electrical interference between implanted medical devices, DBS and cochlear implants may be safe and compatible in the same patient if necessary precautions are taken.

(c) 2015 S. Karger AG, Basel

\section{Background and Importance}

Advancements in technology and an aging population have led to an increasing use of implantable medical devices. An example is the cochlear implant, an electronic device that improves hearing capability in patients with bilateral severe to profound sensorineural hearing loss. As of December 2010, approximately 219,000 patients worldwide have cochlear implants. In the United States, roughly 42,600 adults and 28,400 children have received them [1]. It is inevitable that clinicians will encounter a patient with Parkinson's disease (PD) and a cochlear implant. Clinicians must recognize that preexisting cochlear implants may interfere with deep brain stimulation (DBS) implantation and performance. In this article, we report the successful microelectrode-guided DBS implantation into bilateral subthalamic nuclei (STN) in a PD patient with preexisting bilateral cochlear implants. We docu-

\section{KARGER 125\%}

(c) 2015 S. Karger AG, Base

$1011-6125 / 15 / 0934-0245 \$ 39.50 / 0$

E-Mail karger@karger.com

www.karger.com/sfn
Thomas J. Buell, MD

Neurosurgery Resident Physician, Department of Neurosurgery

University of Virginia Health System, PO Box 800212

Charlottesville, VA 22908 (USA)

E-Mail tjb4p@hscmail.mcc.virginia.edu 
Fig. 1. Preoperative axial MR imaging of deep brain nuclei after cochlear implant magnet removal. a Axial T2-weighted MRI turbo spin-echo sequence depicting STN (arrow). b Axial MRI fast gray matter acquisition $\mathrm{T} 1$ inversion recovery sequence depicting globus pallidus internus (arrow), but the image is significantly degraded with artifact from the cochlear implants despite magnet removal.

Fig. 2. Microelectrode recording. This image demonstrates microelectrode recordings along the right DBS trajectory. a Microelectrode recordings from thalamus, STN, and STN + active cochlear implant (CI). b Microelectrode recordings with time upscaled ( $2 \mathrm{~ms}$ ) showing an action potential from individual neurons in thalamus, STN, and STN + active CI. Activation of the cochlear implant distorts STN microelectrode recordings at a frequency equal to the cochlear implant's total stimulation rate $(7.2 \mathrm{kHz})$. The total stimulation rate is the frequency of the biphasic current pulse that the cochlear implant delivers. It is calculated by multiplying the per channel rate $(900 \mathrm{~Hz})$ by the number of maxima $(\mathrm{n}=8)$ [11]. c Microelectrode recording from deep nuclei showing a transition between true nuclei recording (off) and the distorted cochlear implant recording (on).
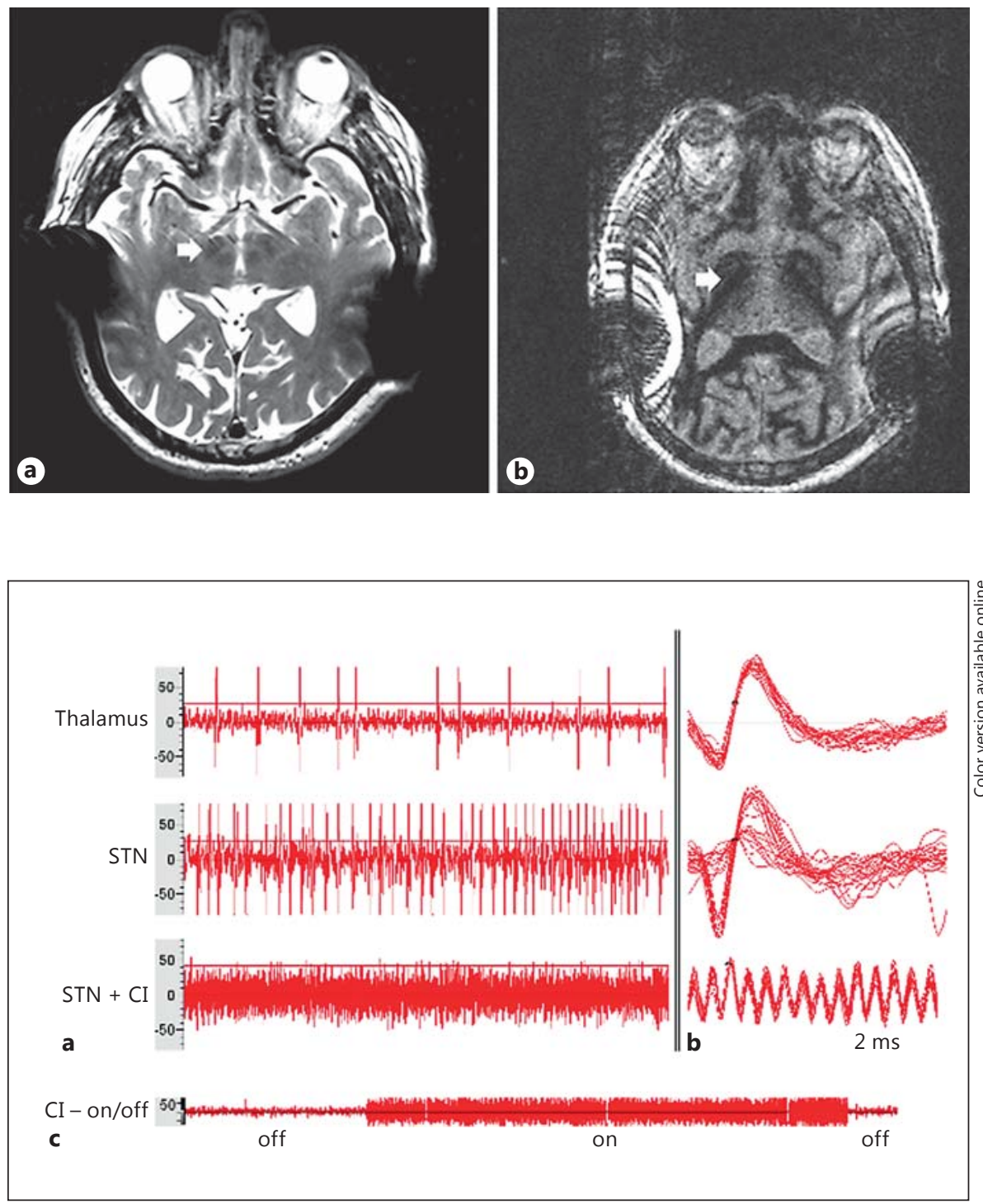

ment electrical interference from the cochlear device on microelectrode recordings during STN DBS implantation and discuss modifications in surgical technique.

\section{Clinical Presentation}

Patient Background

A 70-year-old male with idiopathic PD for over a decade and bilateral severe to profound sensorineural hearing loss presented for DBS surgery. The patient's hearing loss was secondary to viral meningitis in 2006 and managed with bilateral cochlear implants. He reported significant benefit from the cochlear implants and denied side effects such as tinnitus, vertigo, or imbalance.

Despite maximum medical therapy, motor fluctuations with rigidity and gait initiation dysfunction became progressively worse. With demonstrated responsiveness to levodopa (UPDRS III 34 to 11; doubled gait speed) and after neuropsychological evaluation revealed no contraindications, DBS surgery was recommended.

\section{Microelectrode-Guided Bilateral STN DBS Implantation}

Two months prior to DBS surgery, the patient's cochlear implant magnets were removed in order to obtain a preoperative MRI (Siemens Avanto 1.5 T, T2-weighted turbo spin-echo and fast gray matter acquisition T1 inversion recovery sequences) for surgical planning. The magnets were replaced the same day following MRI. In spite of magnet removal, there was significant artifact that made targeting STN more favorable than globus pallidus internus (fig. 1).

The patient underwent frame-based, stereotactic microelectrode-guided insertion of DBS leads (Medtronic Inc., Minneapolis, Minn., USA, 3389S-40) into STN bilaterally. After frame place- 

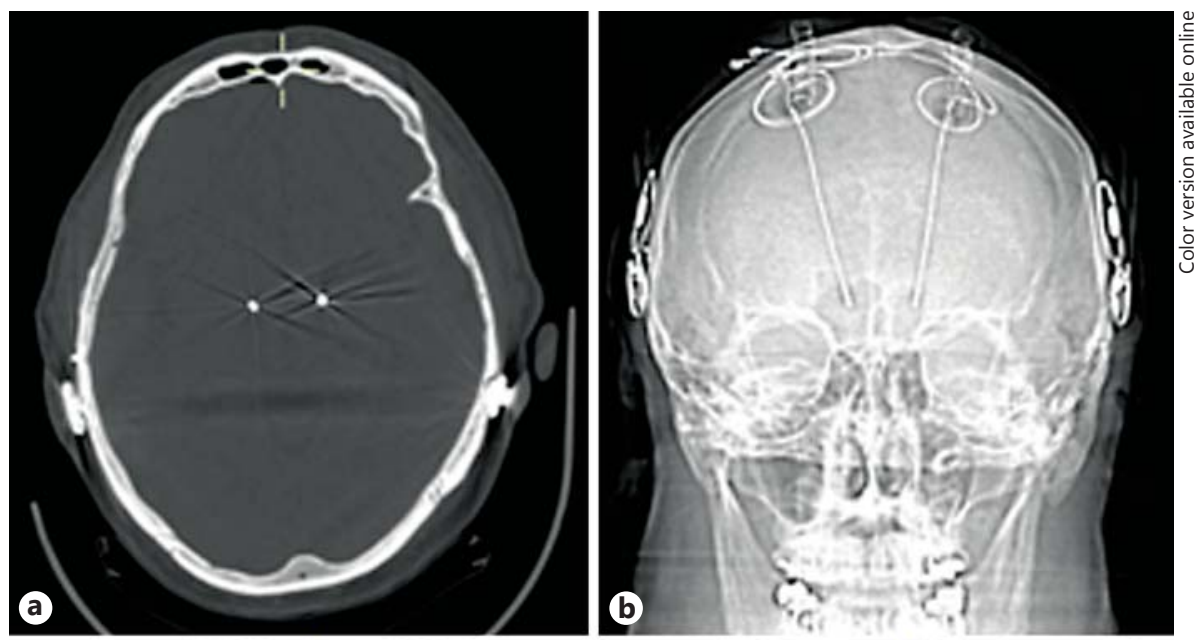

Fig. 3. Postoperative CT head bone window (a) and scout view depict preexisting bilateral cochlear implants after successful microelectrode-guided STN DBS implantation (b). Using Medtronic StealthStation, we fused the postoperative CT head to the preoperative MRI brain. Reconstructed coronal images reveal satisfactory placement of DBS electrodes into the right STN (c) and left STN (d).
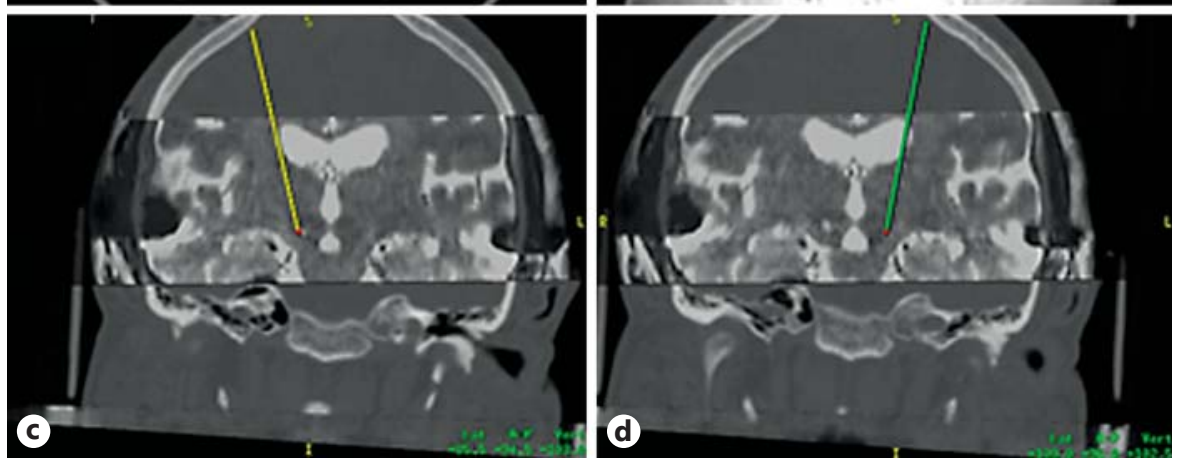

ment with local anesthesia, a volumetric CT was fused to the preoperative MRI for stereotactic planning using direct targeting of STN from T2-weighted MRI. During the surgery, the patient's right cochlear device was turned off, but the left device remained active in order to communicate intraoperatively. Notably, the active left cochlear implant interfered with microelectrode recordings during STN lead placement. After turning off the left cochlear device, microelectrode-guided technique proceeded (fig. 2), and characteristic subthalamic signals were recorded.

While undergoing intraoperative test macrostimulation, the patient's left cochlear implant was reactivated, so the patient could hear and interact with the surgical team. Right STN intraoperative test stimulation yielded transient paresthesias in the left hand and forearm without corticospinal activation. Left STN intraoperative test stimulation suppressed the patient's right leg tremor. After satisfactory macrostimulation testing, the electrodes were anchored and their position was confirmed with fluoroscopy. On postoperative day 1 , the patient was discharged home after CT imaging. DBS electrode positions were verified by fusing the postoperative CT images with the preoperative MRI (fig. 3). The implanted pulse generator was placed during a second-stage operation 3 weeks later. Care was taken to tunnel the lead extensions posterior to the cochlear implant internal receiver.

\section{Postoperative Outcome}

At 4 months, the patient reported improvement in PD symptoms with the following DBS settings: both left and right DBS were set to unipolar configuration with amplitude $1.2 \mathrm{~V}$, pulse width 60 $\mu$ s, and frequency $140 \mathrm{~Hz}$. The patient decreased his levodopa requirement by almost $50 \%$.

Since the DBS surgery, the patient continued to report benefit from his Nucleus Freedom cochlear implants (Cochlear Corp., Sydney, N.S.W., Australia). He denied change in his hearing. No distorted sounds were heard in either ear. His device settings have remained unchanged. Even though the manufacturer (Cochlear Corp.) warns of neurostimulation in the physician packet insert: 'Do not use neurostimulation directly over the cochlear implant. High currents induced into the electrode lead can cause tissue damage to the cochlea or permanent damage to the implant' [2], the patient did not report adverse effects from the device.

\section{Discussion and Literature Review}

As technology advances, an increasing number of PD patients considering DBS will also have preexisting implanted electrical devices. Before implanting DBS electrodes, clinicians should be aware of the risk for electromagnetic interference between implanted electrical devices. Medtronic Inc. reports possible device interactions between DBS systems and cardiac pacemakers, implant- 
Table 1. Previous case reports of patients with both DBS and a cochlear implant

\begin{tabular}{|c|c|c|c|c|c|}
\hline $\begin{array}{l}\text { St. Martin } \\
\text { and Hirsch [8] }\end{array}$ & $\begin{array}{l}\text { 57-year-old male with } \\
\text { PD status post DBS } \\
\text { after unsuccessful } \\
\text { gamma knife } \\
\text { pallidotomy; } \\
\text { developed severe } \\
\text { sensorineural hearing } \\
\text { loss }\end{array}$ & $\begin{array}{l}\text { Medtronic Activa, } \\
\text { bilateral thalamus }\end{array}$ & $\begin{array}{l}\text { Nucleus Contour, } \\
\text { unilateral (left ear) }\end{array}$ & $\begin{array}{l}\text { Placement of superior } \\
\text { pinna incision and } \\
\text { internal receiver had to } \\
\text { avoid the DBS } \\
\text { extension wires }\end{array}$ & $\begin{array}{l}\text { Successful cochlear } \\
\text { device implantation; } \\
\text { no device } \\
\text { interference }\end{array}$ \\
\hline $\begin{array}{l}\text { De Los Reyes } \\
\text { et al. [9] }{ }^{1}\end{array}$ & $\begin{array}{l}\text { 69-year-old male with } \\
\text { sensorineural hearing } \\
\text { loss status post } \\
\text { cochlear implant; } \\
\text { essential tremor with } \\
\text { difficulty writing, } \\
\text { brushing teeth, and } \\
\text { feeding }\end{array}$ & $\begin{array}{l}\text { Medtronic lead } \\
\text { model 3387, left } \\
\text { ventrolateral } \\
\text { thalamic nucleus }\end{array}$ & $\begin{array}{l}\text { Unilateral (right } \\
\text { ear) }\end{array}$ & $\begin{array}{l}\text { Removal of cochlear } \\
\text { magnet for } \\
\text { preoperative imaging } \\
\text { and surgery; MRI with } \\
\text { significant artifact; CT } \\
\text { required for DBS } \\
\text { targeting; magnet } \\
\text { replaced after surgery }\end{array}$ & $\begin{array}{l}\text { Postoperative CT } \\
\text { head well-positioned } \\
\text { DBS lead; no device } \\
\text { interference }\end{array}$ \\
\hline $\begin{array}{l}\text { Cif et al. } \\
{[10]}\end{array}$ & $\begin{array}{l}\text { 8-year-old boy with } \\
\text { Mohr-Tranebjærg } \\
\text { syndrome (deafness, } \\
\text { dystonia, optic } \\
\text { neuropathy) status } \\
\text { post cochlear implant } \\
\text { now with worsening } \\
\text { dystonia }\end{array}$ & $\begin{array}{l}\text { Medtronic model } \\
3389, \text { bilateral } \\
\text { globus pallidus } \\
\text { internus }\end{array}$ & $\begin{array}{l}\text { Nucleus } 24 \text { ST, } \\
\text { unilateral }\end{array}$ & $\begin{array}{l}\text { Cochlear implant } \\
\text { removed } \\
\text { preoperatively and } \\
\text { reimplanted } 8 \text { months } \\
\text { after DBS surgery }\end{array}$ & $\begin{array}{l}\text { Good relief of } \\
\text { dystonia; no device } \\
\text { interference }\end{array}$ \\
\hline
\end{tabular}

able defibrillators, cochlear implants, and other active implanted devices in their prescriber manual [3].

Serious complications have occurred after exposure of DBS systems to high-energy electromagnetic fields. Nutt et al. [4] report the case of a PD patient who suffered permanent diencephalic and brainstem lesions after receiving microwave diathermy near his STN DBS lead during a dental procedure. The authors concluded that the diathermy induced a radiofrequency current, which heated the electrodes and destroyed nearby CNS tissue. The patient was left in a vegetative state. In another case report, Yamamoto et al. [5] describe a patient who suffered an unexpected thalamotomy near his implanted DBS after cardioversion. The patient had a radiofrequency-coupled DBS system. During cardioversion, the patient's radiofrequency receiver transmitted the external cardioversion current, causing the thalamotomy.

In spite of these risks, DBS and other electromagnetic devices have been successfully implanted into the same patient $[6,7]$. In our patient, there were no adverse effects that would suggest electrical interference between his cochlear implants and STN DBS electrodes. This may be because of the distance between the devices and their relatively low, localized amount of electrical stimulation. Other cases of patients having successful implantation of both DBS and cochlear implants have been reported using different techniques (table 1).

St. Martin and Hirsch [8] reported a PD patient with DBS who later underwent cochlear device implantation for severe sensorineural hearing loss.

De Los Reyes et al. [9] reported a patient with a unilateral cochlear implant and essential tremor that required contralateral thalamic DBS. Even though the cochlear implant magnet was removed to obtain preoperative MRI, the study was contaminated with artifact and required CT targeting. Details of microelectrode recording were not provided.

Cif et al. [10] reported an 8-year-old boy with MohrTranebjærg syndrome (deafness, dystonia, optic neuropathy) and a unilateral cochlear implant. The cochlear 
device was removed preoperatively and reimplanted 8 months after DBS surgery. There was no device interference and the patient's dystonia dramatically improved with DBS.

Based on our experience and after literature review, we found that there are several necessary technique modifications in order to perform successful DBS surgery in patients with preexisting cochlear implants. First, it is imperative that the DBS clinicians work together with the patient's otologist in order to coordinate magnet removal/replacement for a preoperative MRI. Despite magnet removal, there still may be significant artifact from the cochlear device and thus CT may be used for targeting purposes. Postoperatively, MRI may not be possible for lead localization if the magnets have been replaced, and so instead, CT must suffice.

Second, avoid damaging the preexisting cochlear implants when tunneling DBS lead extensions past the cochlear device's internal receiver. We used fluoroscopy to safely identify and avoid the internal receiver.
Finally, intraoperative patient communication may require a functional cochlear implant, so we recommend replacing the magnets prior to DBS surgery. Even though an activated cochlear implant will interfere with microelectrode recordings, it can be temporarily deactivated during surgery. After satisfactory DBS lead placement, the cochlear implant can be reactivated to facilitate patient-to-surgeon communication for intraoperative stimulation testing.

\section{Conclusions}

Subthalamic DBS can be successfully performed in PD patients with preexisting cochlear implants. Preexisting cochlear implants should not be regarded as a contraindication to DBS as the magnet can be easily removed and replaced in the outpatient setting for MR imaging, and electrical interference during microelectrode recordings can be mitigated by turning off the implant.

\section{References}

1 National Institute on Deafness and Other Communication Disorders: Cochlear Implants. http://www.nidcd.nih.gov/health/ hearing/pages/coch.aspx (accessed November 3,2013 ).

2 Cochlear: Nucleus cochlear implants: physician's packet insert. http://products.cochlearamericas.com/sites/default/files/Nucleus_ Insert_web.pdf (accessed November 4, 2013).

3 Medtronic Corporation: Medtronic DBS therapy implanted neurostimulators - information for prescribers. http://professional. medtronic.com/wcm/groups/mdtcom_sg/ @mdt/@neuro/documents/documents/dbsifp.pdf (accessed November 2, 2013).

4 NuttJG, Anderson VC, PeacockJH, et al: DBS and diathermy interaction induces severe CNS damage. Neurology 2001;56:1384-1386.
5 Yamamoto T, Katayama Y, Fukaya C, et al: Thalamotomy caused by cardioversion in a patient treated with deep brain stimulation. Stereotact Funct Neurosurg 2000;74:73-82.

-6 Senatus PB, McClelland S 3rd, Ferris AD, et al: Implantation of bilateral deep brain stimulators in patients with Parkinson disease and preexisting cardiac pacemakers. Report of two cases. J Neurosurg 2004;101:1073-1077.

7 Capelle HH, Simpson RK Jr, Kronenbuerger M, Michaelsen J, Tronnier V, Krauss JK: Long-term deep brain stimulation in elderly patients with cardiac pacemakers. J Neurosurg 2005;102:53-59.

-8 St Martin MB, Hirsch BE: Cochlear implantation in a patient with bilateral deep brain stimulators. Laryngoscope 2007;117:183185.
-9 De Los Reyes K, Chandrasekhar SS, Tagliati M, Alterman R: Successful implantation of a deep brain stimulator for essential tremor in a patient with a preexisting cochlear implant: surgical technique: technical case report. Neurosurgery 2010;66(6 supploperative):372; discussion 372.

10 Cif L, Gonzalez V, Garcia-Ptacek S, James S, Boetto J, Seychelles A, Roujeau T, Moura De Ribeiro AM, Sillon M, Mondain M, Coubes P: Progressive dystonia in Mohr-Tranebjærg syndrome with cochlear implant and deep brain stimulation. Mov Disord 2013;28:737738.

11 Cochlear: Clinical Guidance Document, pp 12-13. http://cochlear-cee-training.org/wordpress/wp-content/uploads/2011/12/231495 ISS3_EN_CSS_Clinical_Guidance_Document.pdf (accessed December 24, 2013). 